\title{
The Role of Using Smartphones on Depression Rate in Retired Elderly
}

\begin{abstract}
Background and Objective: Aging period is associated with potential threats such as loneliness and isolation. One of the most common mental disorders in the elderly is cognitive disorders and depression. Therefore, the purpose of this study was to investigate the role of smartphones use in depression in the retired elderly people of Yazd.

Materials and Methods: This cross-sectional study was conducted on 408 elderly people who were covered by the retirement center of Yazd province in 2018. The samples were selected through random sampling method. The questionnaires included demographic characteristics, internet usage, and GDS (Depression Scale). After data collection, analysis was performed using SPSS software version 18 and Mann-Whitney, Kruskal-Wallis and Chi-square.

Results: $74.1 \%$ (74 people) of the elderly who used the Internet had no depression and $38.4 \%$ (60 people) of the elderly reported the reason for using the mobile phone is obtaining information and severe depression in this group was less than the other group ( $8.3 \%$ including 5 people). Mean depression score by gender ( $p$ $=0.046)$, marital status, education, income, lifestyle $(p \leq 0.001)$, and reason for internet use $(p=0.043)$ were significantly different in the two groups of Smartphone and non-Smartphone users.

Conclusion: Given the results and the positive role of smart phones in reducing depression in the elderly, programs for the elderly need to be designed through social networks. Using the Internet and social networks can help increase the respect and confidence of older people at community level, and isolate and loneliness caused by child marriage, death of a partner, and physical and mental disabilities can be Reduced by using a Smartphone and improved the mental health of the elderly, also through proper policymaking and activation of support systems to improve their well-being, efforts can be made to achieve a favorable period for them. Keywords: Elderly, Smartphone, Depression, Retirees

Paper Type: Research Article.
\end{abstract}

Citation (Vancouver): Yoshany N, Mazloomy-Mahmoodabad S, Mihanpour H, Seyed-khameshi S, Gerayllo S, Nabil A. The Role of Using Smartphones on Depression Rate in Retired Elderly. Iran J Health Educ Health Promot. Spring 2020;8(3): 240-248. [Persian]x

- Citation (APA): Yoshany N., Mazloomy-Mahmoodabad S., Mihanpour H., Seyedkhameshi S., Gerayllo S, Nabil A. The Role of Using Smartphones on Depression Rate in Retired Elderly. Iranian Journal of Health Education \& Health Promotion., 8(3)240-248 . [Persian]
Nooshin Yoshany

$\mathrm{PhD}$ in Health education and health promotion, Social Determinants of Health Research Center, Department of Health Education and Health Promotion, School of Public Health, Shahid Sadoughi University of Medical Sciences, Yazd, Iran

Seyed-Saeed Mazloomy-Mahmoodabad $\mathrm{PhD}$ in Health education and health promotion, Social Determinants of Health Research Center, School of Public Health, Shahid Sadoughi University of Medical Sciences, Yazd, Iran.

Hamideh Mihanpour

MSc in occupational health, department of occupational health, school of public health, Shahid Sadoughi University of medical sciences, Yazd, Iran.

Somayeh-sadat Seyed-khameshi BSc in Public Health, Social Determinants of Health Research Center, School of Public Health, Shahid Sadoughi University of Medical Sciences, Yazd, Iran.

Sakineh Gerayllo

* PhD in Health Education and Health Promotion, Department of health, School of Public Health, Golestan Faculty of Medical Sciences, Gorgan, Iran. (Corresponding author): Email: Gerayllo65@yahoo.com

Asghar Nabil

PhD student in tourism management, Yazd Science and arts university, Yazd, Iran.

Received: 2019/12/7

Accepted: 2020/03/18

Doi: 10.29252/ijhehp.8.3.240 


\section{نقش استفاده از كوشىهاى هوشمند در ميزان افسردكى سالمندان بازنشسته}

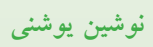

دكترى تخصصى آموزش بهداشت و ارتقاء سلامت،

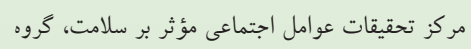

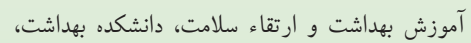
دانشكاه علوم يزشكى شهيد صدوقى يزد، يزد، ايران. سيد سعيد مظلومى محمو دآباد دكترى تخصصى آموزش بهداشت و مارتيد ارتقاء سلامت،

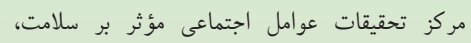

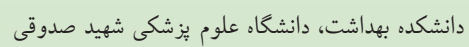
يزد، يزد، ايران. حميده ميهن بور كارشناسى ارشد بهداشت حرفه اي، گروه بهداشت حرفه

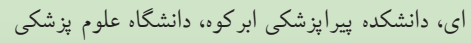

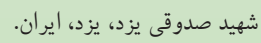

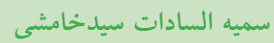
كارشناس بهداشت عمومى، مركز تحقيقات عوامل

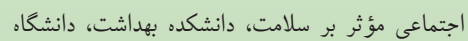
علوم يزشكى شهيد صدوقى يزد، يزد، ايران. سكينه كرايلو * دكترى تخصصى آموزش بهداشت و ارتقاء سلامت،

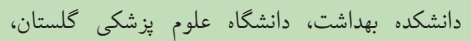
كر گان، ايران.(نويسنده مسئول):

\section{Email: gerayllo65@yahoo.com}

اصغر نبيل

دانشكاه علم و هنر يزد، يزد، ايران

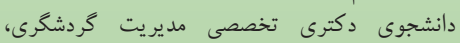

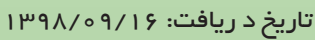

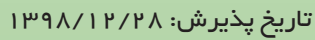

\section{جكيده}

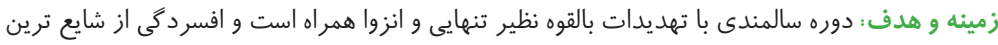

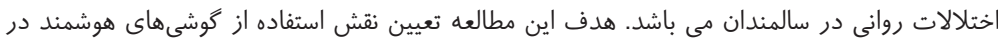

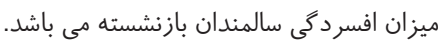

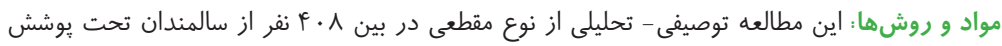

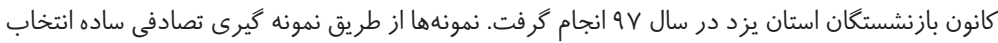

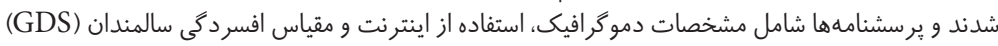

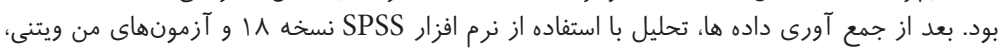
كروسكال واليس و كاى اسكوئر انجام گرقائ.

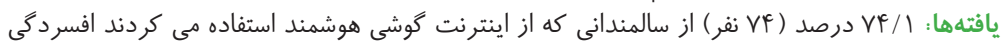

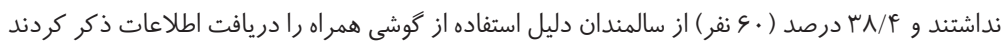

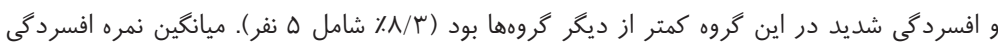

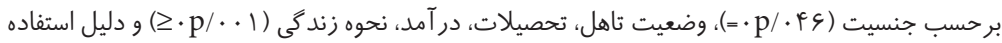

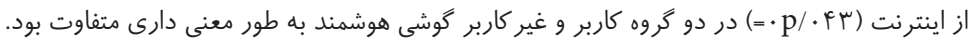

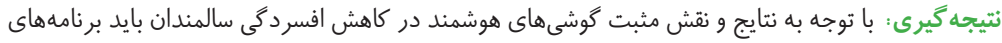

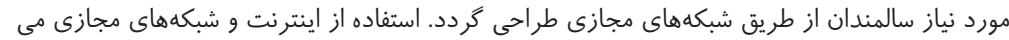

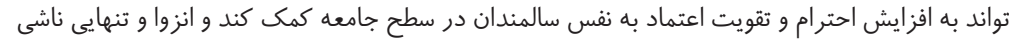

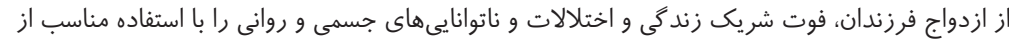

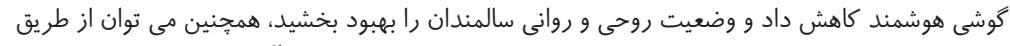

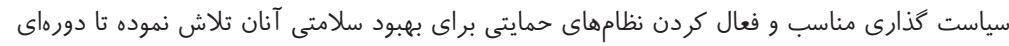

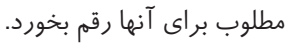

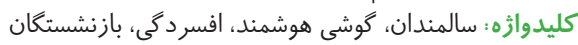
نوع مقاله : مطالعه يخوهشى.

4 استناد (ونكوور): يوشنى ن، مظلومى محمود آباد س، ميهن يور ح، سيدخامشى س، كرايلو س، نبيل ا.

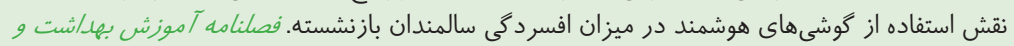

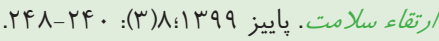

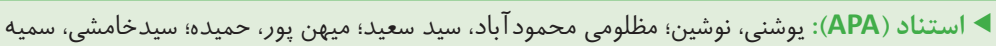

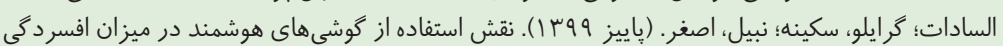

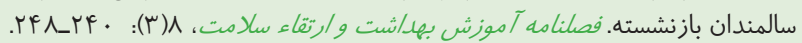


كه داراى سطح سلامت پايين ترى هستند و به خصوص از ضعف سلامت روانى رنج مى برند، شبكة اجتماعى كو جكتر و در نتيجه دوستان صميمى كمترى دارند (19).

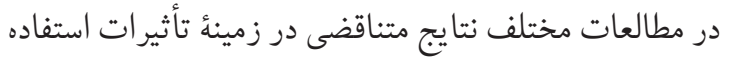

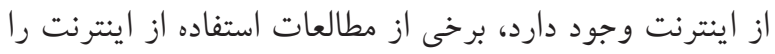

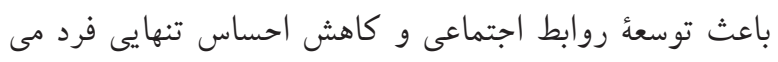

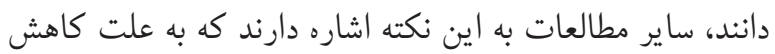

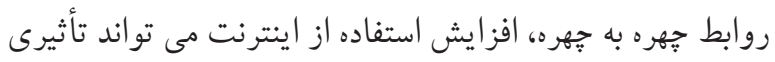

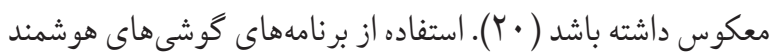
به عنوان يك روش جديد براى كنترل افسردگى به شمار مى رود

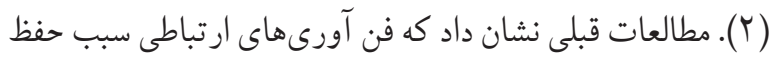
روابط اجتماعى مى شود و تنهايى، افسردگى، عزت نفس و حمايت

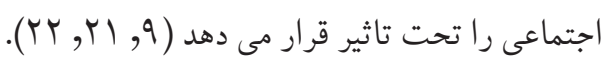

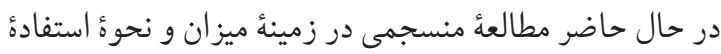

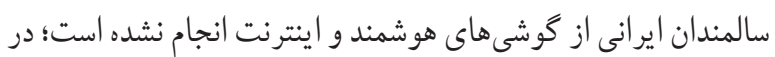

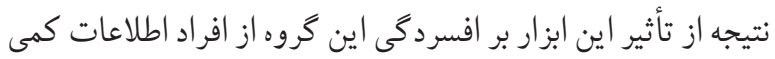

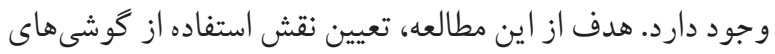
هوشمند در ميزان افسردگى سالمندان بازنشسته مى باشد.

\section{ورش بروسى} مطالعه حاضر از نوع توصيفى و تحليلى بود كه به صورت مقطعى در

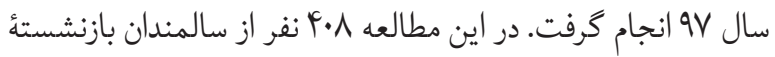
بخش دولتى شهر يزد (ادراه برق، مخابرات، آب و فاضلاب، بانك،

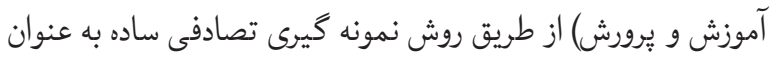

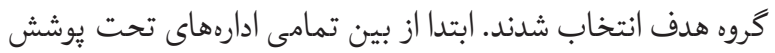
كانون بازنشستگان استان يزد، ه اداره به طور تصادفى انتخاب و

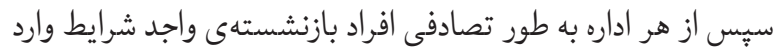

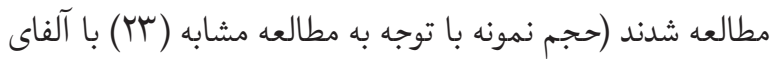

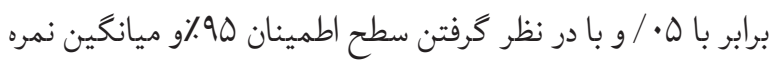

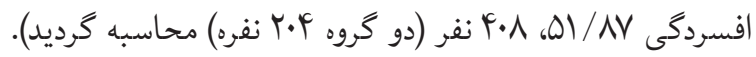

در سالهاى اخير، تلفنهاى همراه به طور فراگير در سراسر جهان استفاده مى شود ( (1). كوشى هوشمند با قابليت هاى بيشرفيته سخت

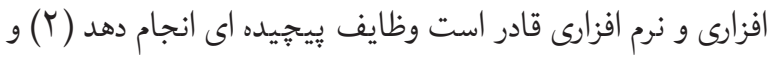
استفاده از اين ابزار بخش جدايى نايذير زندگى افراد سراسر جهان

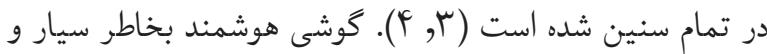
قابل حمل بودن، دسترسى به اينترنت و ويزگكى هاى ارتباط مستقيم

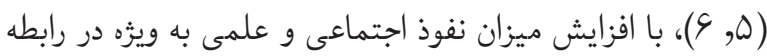

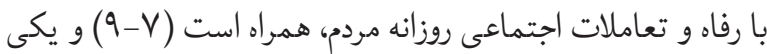

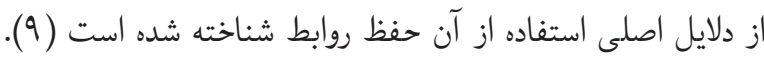
طبق برآوردهاى انجام شده در كشورهاى بيشرفته افراد بالاى 90

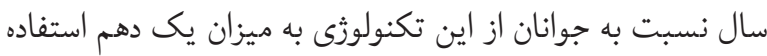

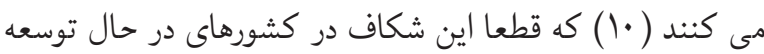
بيشتر است (1). خوشبختانه نسل آينده سالمندى كه هـم اكنون

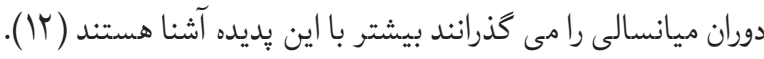

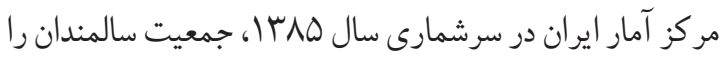

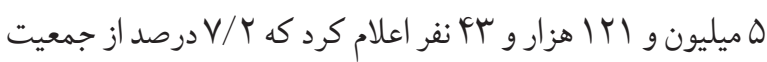

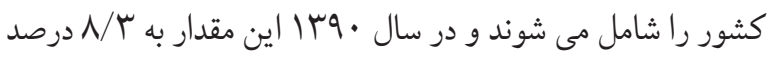

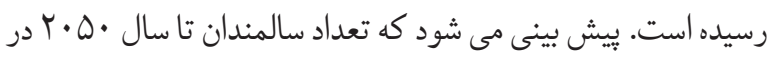

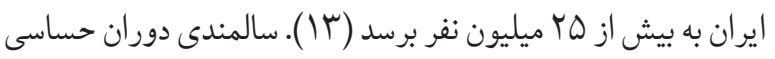

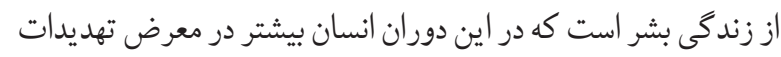

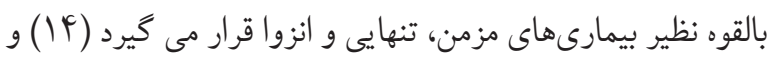

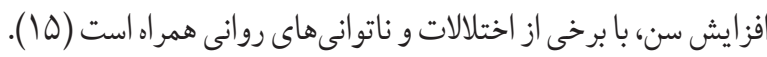

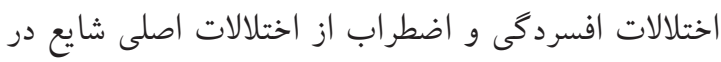

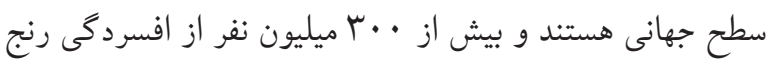

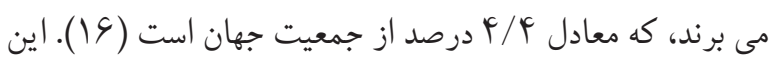
در حالى است كه شايع ترين اختلالات روانى در سالمندان، اختلالات

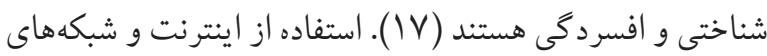

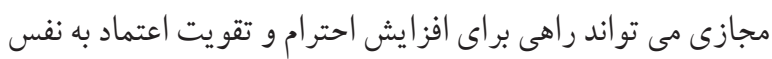

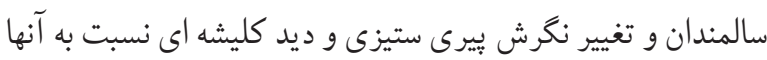
در سطح جامعه باشد (1) (1). متخصصين معتقد هستند كه افرادى ني 
نتايج حاصل از يزوهش نشان داد كه ميانگين و انحر اف معيار

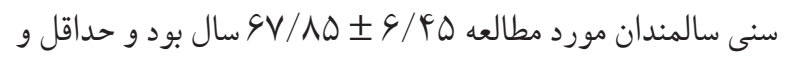

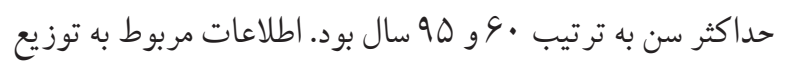

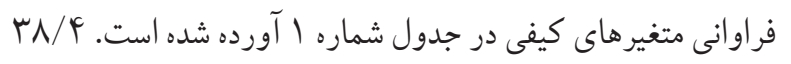

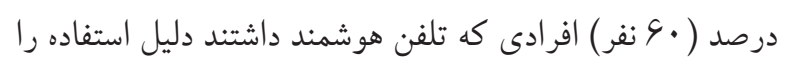

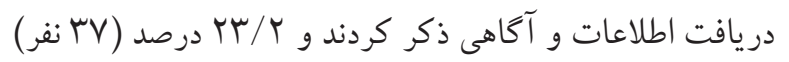
جهت سر گرمى استفاده مى كردند.

جدول ا : توزيع فراوانى متغير هاى كيفى دموگرافيى

\begin{tabular}{|c|c|c|c|}
\hline درصد & فراوانى & متغير & \\
\hline$V \mu / r$ & $r 99$ & مرد & \multirow{2}{*}{ جنسيت } \\
\hline$r s / V$ & 1.9 & زن & \\
\hline $1 / 4$ & ro & مجرد & \multirow{4}{*}{ تأهل } \\
\hline $11 / 1$ & וזr & 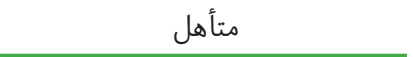 & \\
\hline $9 / 8$ & rq & همسر از دست داده & \\
\hline$\cdot / V$ & r & مطلقه & \\
\hline$m F / \Lambda$ & Ifr & زير دييلم & \multirow{4}{*}{ تحصيلات } \\
\hline$r q / q$ & س & ديلم و كاردانى & \\
\hline $41 / 1$ & $\wedge \varsigma$ & كارشناسى و ارشد & \\
\hline$r / r$ & IV & 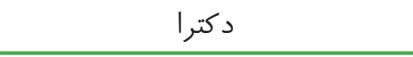 & \\
\hline $1 f / V$ & s. & كمتر از · · هزار تومان & \multirow{4}{*}{ 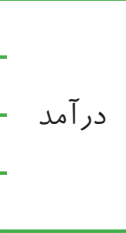 } \\
\hline $11 / 9$ & $\checkmark V$ & V ت . . & \\
\hline$r \cdot / 9$ & Irs & بيش از | ميليون تا r ميليون تومان & \\
\hline$r \Delta / \Delta$ & Ifo & بيش از r ميليون تومان & \\
\hline$\Lambda T / r \Delta$ & ל צמr & 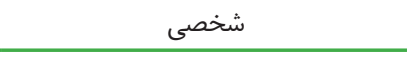 & \multirow{2}{*}{ نوع مسكن - } \\
\hline $1 V / 90$ & Vr & استيجارى & \\
\hline$r \cdot / r$ & Isf & 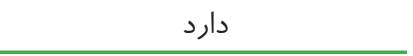 & \multirow{2}{*}{ هوشمنايل } \\
\hline$\Delta q / \wedge$ & pFF & 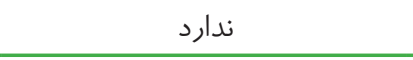 & \\
\hline rv & 101 & همراه با همسر & \multirow{6}{*}{ 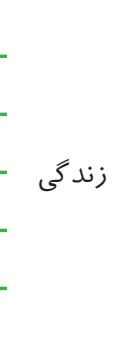 } \\
\hline $41 / 1$ & 191 & با همسر و فرزندان مجرد & \\
\hline$r / r$ & 11 & فوت همسر و زندگى با فرزند مجرد & \\
\hline$\mu / r$ & 11 & با همسر در منزل فرزند متاهل & \\
\hline r & $\wedge$ & بدون همسر در منزل فرزند متاهل & \\
\hline $1 \pi / 0$ & $\Delta \Delta$ & تنها & \\
\hline
\end{tabular}

نتايج حاصل از آزمون كاى اسكوئر نشان داد كه شدت افسردگى
معيارهاى ورود به مطالعه شامل سن بالاى • ·، سكونت در شهر

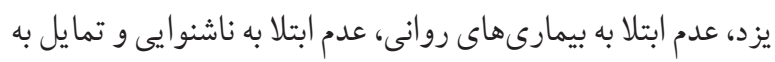

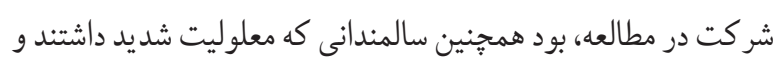
به هر دليل قادر به پِاسخ كو يى به سو الات نبودند از مطالعه خارج شدند.

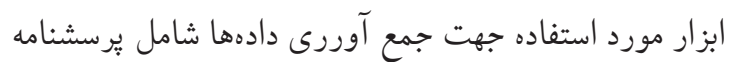
مشخصات دمو كرافيك شامل جنسيت، تاهل، تحصيلات، در آمد

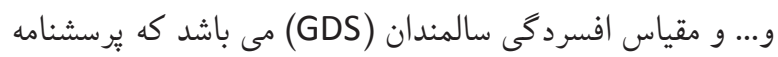
افسردگى سالمندان توسط يساو يج براى ارزيابى افسردخى سالمندان

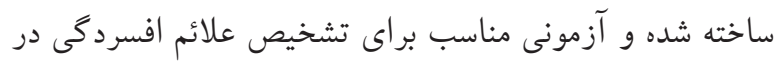

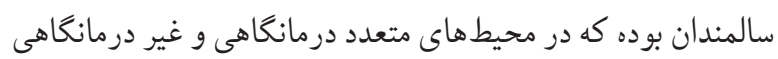

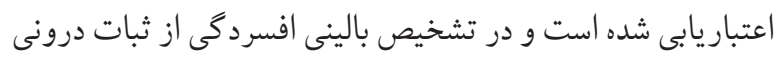

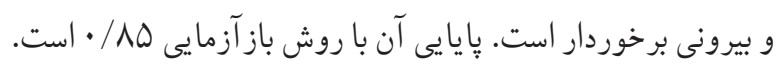

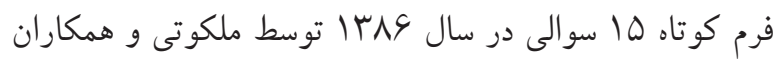

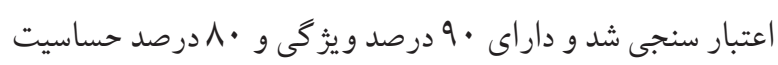

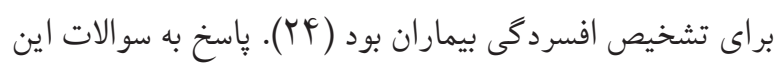

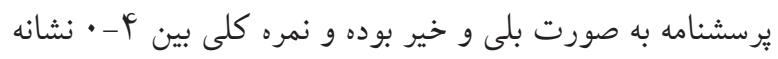

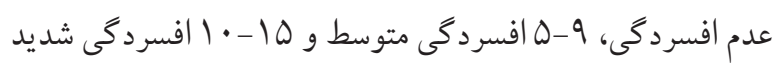
مى باشد. پايايى فرم ها سوالى اين آزمون در جامعه ى سالمندى

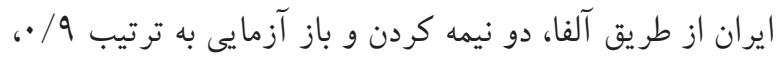

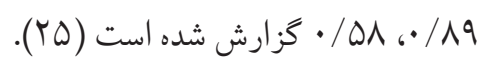
اين مطالعه با كد اخلاق شد. جهت جمع آورى دادهها ابتدا رضايت نامه آكاهانه توسط افراد

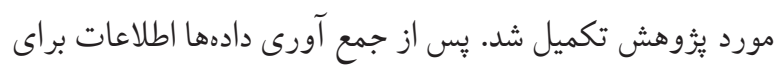

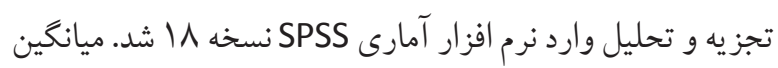

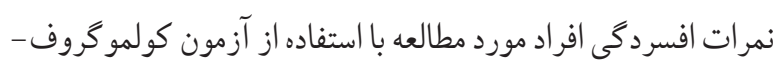

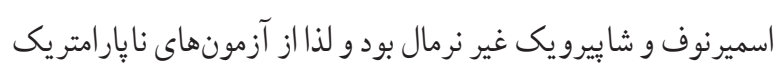
من ويتنى، كروسكال واليس و كاى اسكوئر استفاده شد. يافته ها

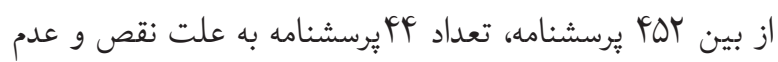

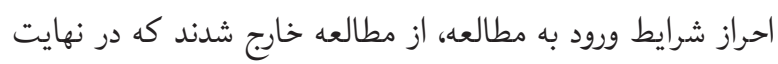

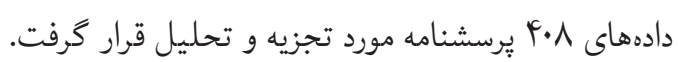


جدول r: نتايج مقايسه متغير هاى تلفن همراه و شدت افسردگى در افراد مورد مطالعه

\begin{tabular}{|c|c|c|c|c|c|c|c|c|}
\hline \multirow{2}{*}{$\begin{array}{l}\text { P value } \\
r \chi\end{array}$} & \multicolumn{2}{|c|}{ 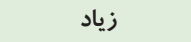 } & \multicolumn{2}{|c|}{ متوسط } & \multicolumn{2}{|c|}{ عدم افسردكى } & \multirow{2}{*}{\multicolumn{2}{|c|}{ متغير }} \\
\hline & درصد & تعداد & درصد & تعداد & درصد & تعداد & & \\
\hline \multirow{2}{*}{.1909} & $10 / r$ & ro & $r N / \uparrow$ & gr & $\varphi s / \mu$ & VA & دارد & \multirow{2}{*}{ كوشى هوشمند } \\
\hline & $\mid N / F$ & is & $r q / \wedge$ & १४ & 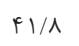 & $1 \cdot r$ & ن ارد & \\
\hline \multirow{2}{*}{. $/$ VFr $^{4}$} & $10 / 9$ & ro & $r s / 9$ & $\Delta \wedge$ & $V F / 1$ & $V^{F}$ & بلى بلى & \multirow{2}{*}{ استفاده از اينترنت } \\
\hline & $1 N / 1$ & +1 & $r N / \Lambda$ & $\Lambda \wedge$ & $\mu r / r$ & 91 & خير & \\
\hline \multirow{4}{*}{$\cdot / r \& V$} & $r \varphi / r$ & 9 & $r \cdot / \Delta$ & 10 & $r \Delta / 1$ & ir & سركرمى & \multirow{4}{*}{ دليل استفاده از اينترنت } \\
\hline & $\Lambda / r$ & $\Delta$ & ro & $r l$ & $\Delta S / V$ & re & آكاهى و كسب اطلاعات & \\
\hline & $\mid r / \Delta$ & r & $+1 / V$ & 1. & $F \Delta / \wedge$ & 11 & ارتباط با دوستان و اقوام & \\
\hline & $r r / 9$ & $\wedge$ & $\kappa r / \mu$ & ir & $r r / q$ & 10 & همه موارد & \\
\hline
\end{tabular}

جدول "ا: نتايج مقايسه ميانگين نمره افسردگى برحسب كاربران گَشى هوشمند با مشخصات دموگرافيك افراد مورد مطالعه

\begin{tabular}{|c|c|c|c|c|c|c|c|c|}
\hline \multirow{3}{*}{ P-value } & \multicolumn{6}{|c|}{ ميانگين نمره افسردگى } & \multirow{3}{*}{\multicolumn{2}{|c|}{ متغير }} \\
\hline & \multicolumn{3}{|c|}{ غير كاربر كوشى هوشمند } & \multicolumn{3}{|c|}{ كاربر كوشى هوشمند } & & \\
\hline & ميانه & دامنه ميان & انحراف معيار 土 ميانكين & ميانه & $\begin{array}{l}\text { دامنه ميان } \\
\text { جاركى }\end{array}$ & انحراف معيار 土 ميانكين & & \\
\hline \multirow{3}{*}{ 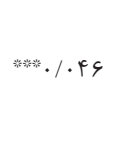 } & $\checkmark$ & r & $s / \Delta \Delta \pm \mu / \mu$. & f & 4 & $\Delta / \cdot \vee \pm f / \cdot \wedge$ & 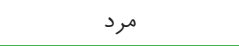 & \multirow{3}{*}{ جنسيت } \\
\hline & $\wedge$ & 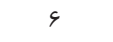 & $s / F \Delta \pm F / F r$ & $s / \Delta$ & $\wedge$ & $s / r \Delta \pm f / V I$ & 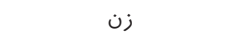 & \\
\hline & & $\cdot / r \cdots$ & & & $.1 .9 \mathrm{~V}$ & & $\mathrm{P}$-value & \\
\hline \multirow{5}{*}{$w^{*} \leq \cdot / \cdots 1$} & $\wedge$ & $\Delta / \vee \Delta$ & $s / V \Delta \pm r / r \Delta$ & 9 & $r / \Delta$ & $\wedge / r \wedge \pm r / 99$ & 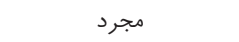 & \multirow{5}{*}{ وضعيت تاهل } \\
\hline & $\checkmark$ & $\Delta$ & $G / r F \pm r / r V$ & f & V & $r / V I \pm r / q r$ & متأهل & \\
\hline & $\checkmark$ & $\Lambda / \Delta$ & $\wedge / \Lambda \pm r / f q$ & 9 & $q / r \Delta$ & $N / 19 \pm \Delta / \cdot r$ & از دست داده & \\
\hline & - & - & - & 1 & - & $\Lambda \pm s / r$ & مطلقه & \\
\hline & & $\leq \cdot / \cdots 1$ & & &.$/ \cdots 1$ & & P-value & \\
\hline \multirow{5}{*}{$w^{*} \leq \cdot / \cdots 1$} & $\checkmark$ & $r / \Delta$ & $V / \cdot \Delta \pm r / \Lambda$ & $\wedge$ & $\wedge$ & $V / q \pm \Delta / \cdot F$ & زير دييلم & \multirow{5}{*}{ سطح تحصيلات } \\
\hline & $s / \Delta$ & $\Delta / r \Delta$ & $\Delta / \wedge \varphi \pm \mu / \cdot \wedge$ & f & $\Delta / \vee \Delta$ & $p / f \pm q r / r q$ & دييلم و كاردانى & \\
\hline & $\wedge$ & - & $\wedge / \cdots \pm|/ F|$ & r & $\wedge$ & $F / f \pm \Delta F / \cdot q$ & كارشناسى و ارشد & \\
\hline & - & - & - & r & $s / 0$ & $f / f \pm f / s \mid$ & 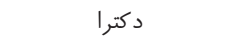 & \\
\hline & & $\leq \cdot / \cdots 1$ & & & $\cdot / V S O$ & & P-value & \\
\hline \multirow{5}{*}{ 米米 $\leq \cdot / \cdots 1$} & $\wedge$ & s & $V / \Delta \pm r / \cdot \wedge$ & $\wedge$ & $\Delta$ & $V / \mathscr{T} \pm \Lambda / r q$ & كمتر از · · هزار تومان & \multirow{5}{*}{ درآمد } \\
\hline & $\checkmark$ & $r / v \Delta$ & $s / \wedge r \pm r / \cdot s$ & $\wedge$ & $\Delta$ & $V / r \pm \cdot V / V r$ & V ت . . & \\
\hline & $V / \Delta$ & $\Delta / r \Delta$ & $\Delta / 9 \Delta \pm r / \mathcal{F}$ & $\Delta$ & V & $\Delta / f \pm f / \mid 1$ & ا تا r ميليون تومان & \\
\hline & $\Delta / \Delta$ & - & $\Delta / \Delta \pm r / \Delta r$ & r & V & $\tau / \Delta \pm V / r \Delta$ & بيش از r ميليون تومان & \\
\hline & & $\leq \cdot / \cdots 1$ & & &.$/ \cdots 1$ & & P-value & \\
\hline \multirow{3}{*}{ 米米米/ $/ 1 \cdot r$} & $\checkmark$ & f & $s / V q \pm r / l 1$ & $\Delta$ & 4 & $\Delta / \Psi \pm \Delta \Delta / V r$ & شخصى & \multirow{3}{*}{ نوع مسكن } \\
\hline & $\Delta / \Delta$ & $s / r \Delta$ & $s / \| F \pm f / V \Delta$ & $V / \Delta$ & $V / r \Delta$ & $s / 4 \pm V \wedge / q$ & استيجارى & \\
\hline & &.$/ 9 \Delta \Delta$ & & &.$/ .40$ & & P-value & \\
\hline
\end{tabular}

* Interquartile Range (IQR) $\quad * *$ Kruskal-Wallis Test $\quad * * *$ Mann-Whitney Test 
استفاده از تلفن هوشمند نيافتند (T9) ولى در مقابل مطالعاتى نيز نشان داد كه هبستكى مثبت و معنى دارى بين ميزان استفاده از

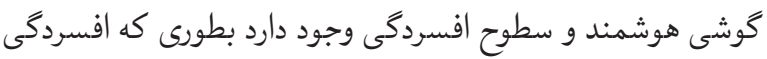
در گروهى كه از گوشى هوشمند استفاده مى كردند بسيار بالاتر از

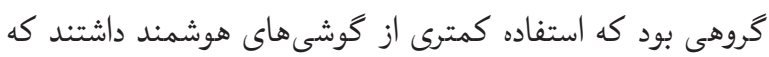

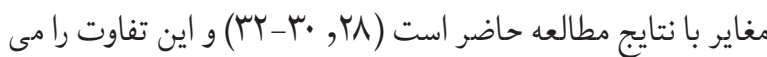
توان به گروه هدف مطالعه كه سالمندان بازنشسته مى باشند مرتبط كرد كه جامعه اين يثوهش متفاوت با مطالعات ذكر شده مى باشد.

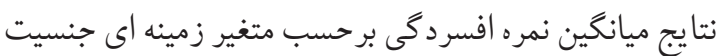

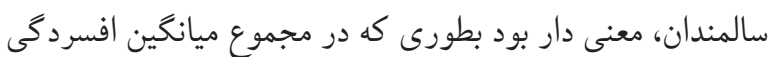

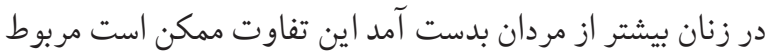

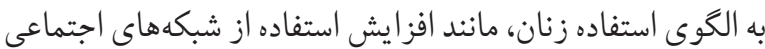
باشد. اين نتايج با مطالعاتى از جمله دميرسى بو همكاران، عليزاده و

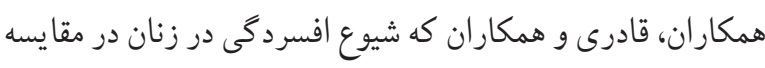

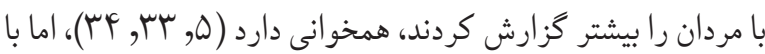
مطالعه امامى نائينى و همكاران مغايرت دارد كه ارتباط معنادارى را هرد

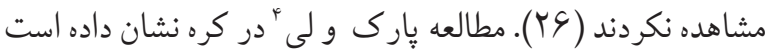
كه زنان بيشتر از مردان اعتياد به گوشىهاى هوشمند دارند (هץ).

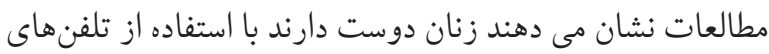

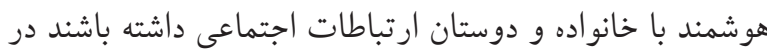

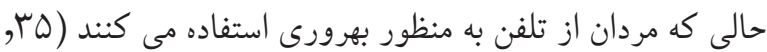
צץ) و همجنين افرادى كه افسردگى، اضطراب و تنهايى دارند،

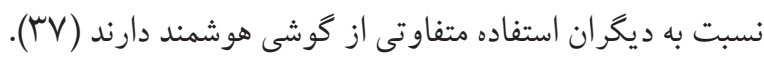
نتايج ميانكين نمره افسردگى برحسب متغير وضعيت سكونت معنى دار نبود با اين وجود كاربرانى كه منزل شخصى داشتند افسردگى كمترى نسبت به سايرين داشتند. اين نتايج با مطالعات

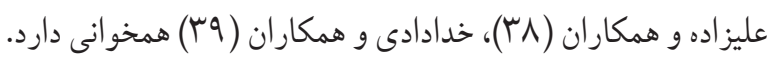
ميانخين نمره افسردگى در متأهلين بطور معنادارى كمتر از ساير كروهها بود و همجنين در افراد مطلقه غير كاربر بيشتر از ساير گروهها مشاهده شد. بنظر مى رسد بهره مندى از وجود همسر مى تو اند فاكتور

3. Demirci K

4. Park N \& Lee H
با داشتن گوشى هوشمند و استفاده از اينترنت ارتباط آمارى معنى

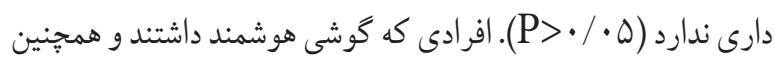

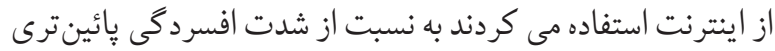

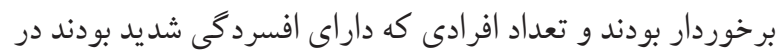

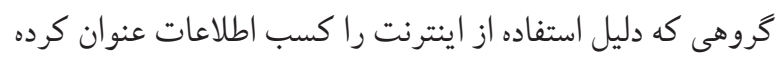

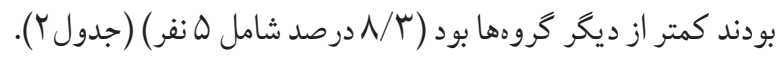
ميانكين نمره افسردگى برحسب جنسيت در هر دو گروه كاربر

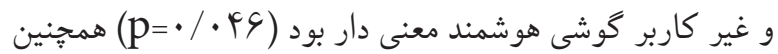

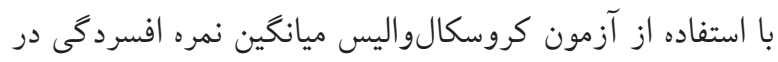

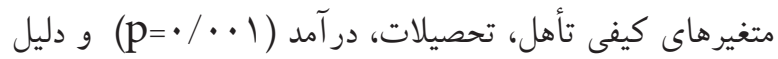

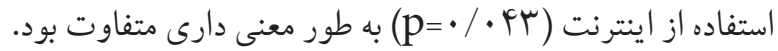
نمره افسردكى در مردان، متاهلين، افراد با تحصيلات و در آمد بالا

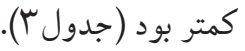

\section{بحث}

مطالعه حاضر با هدف تعيين نقش استفاده از كوشىهاى هوشمند در ميزان افسردكى سالمندان بازنشسته انجام شد. طبق يافته ها، شدت افسردگى در افرادى كه از گوشى هوشمند استفاده مى كردند

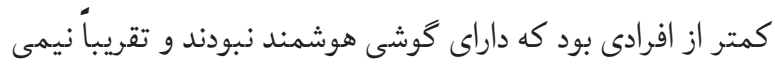

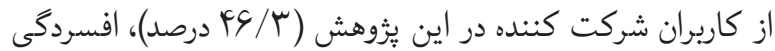
نداشتند كه نسبت به مطالعه امامى نائينى و همكاران كه در سالمندان انجام شده شرايط بهترى دارند (Y)) و همجنين مطالعه على يور و و

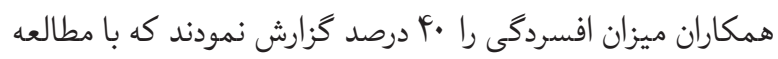

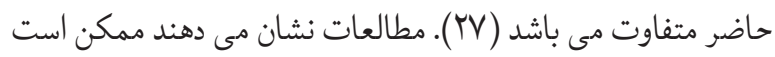
استفاده از تلفن هاى هوشمند و سركرم شدن با برنامههاى آن، افراد را

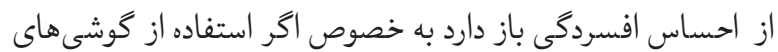

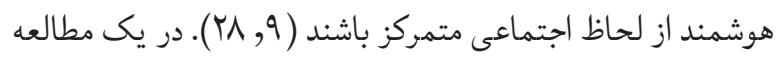

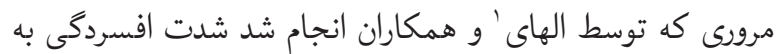
طور گسترده با استفاده از گوشى هاى هوشمند مرتبط بود ( ( ) با اين

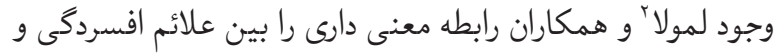


همجنين شدت افسردگى در سالمندانى كه از اينترنت استفاده

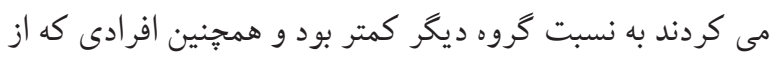
اينترنت جهت كسب اطلاعات استفاده مى كردند كمتر از ساير ين در گروه افسردگى شديد قرار داشتند. اين گونه استدلال مى شود كه

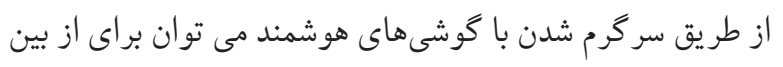

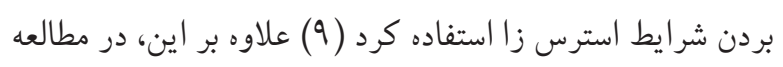

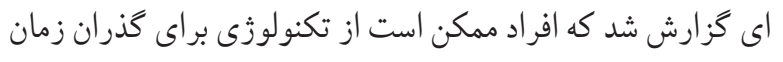

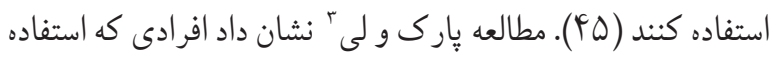
از كوشىهاى هوشمند را براى دستيابى به انكيز ههاى دلخواه استفاده

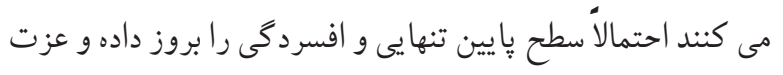

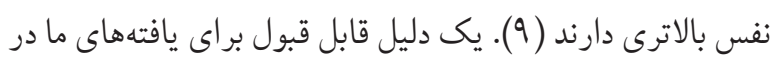
مورد افسردگى اين است كه كذران وقت با كوشى هاى هوشمند

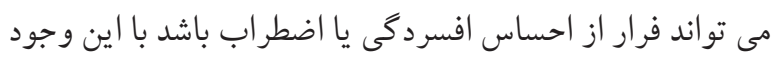

$$
\text { هدف از استفاده از اينترنت بسيار مهم است. }
$$

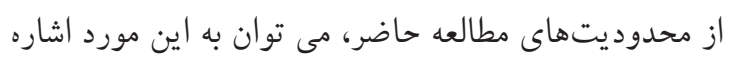

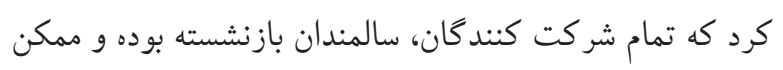

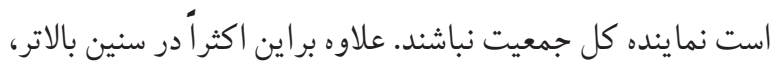

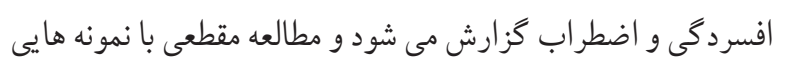

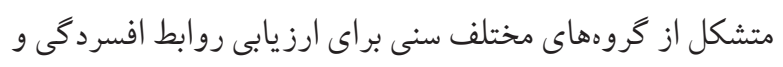
استفاده از كوشى هوشمند مورد نياز است. نتيجه كيرى با توجه به نتايج و نقش مثبت كوشىهاى هوشمند در كاهش

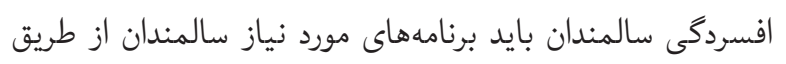

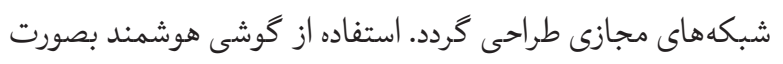
استفاده متناسب و متوسط، ممكن است براى بهبود وضعيت روحى

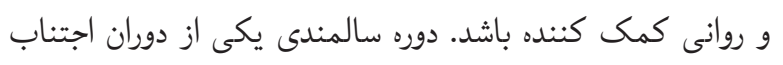

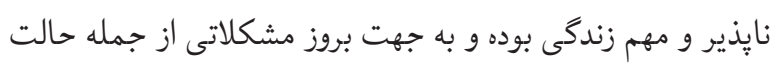

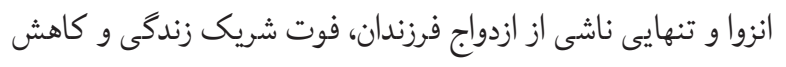

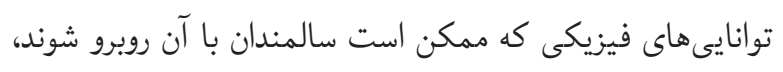

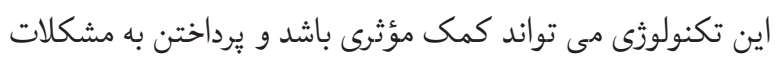

3. Park N \& Lee H
اساسى و حفاظتى در زمينه حمايت و مواجهه با مشكلات زندكى باشد و نقش محافظت كننده افسردكى را ايفا نمايد. اما طبق نتايج

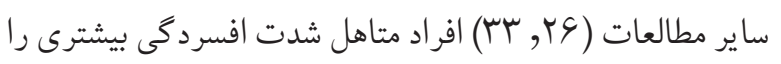

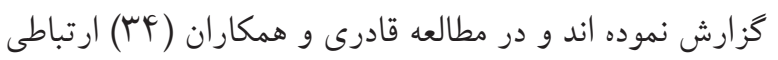

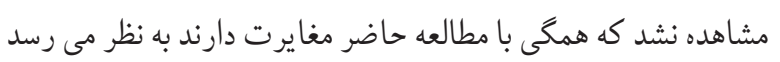

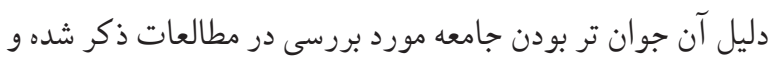
وجود تنشها و روابط نامطلوب همسران و تشديد افسردگى باشد. در زمينه تحصيلات نيز ميزان افسردگى در افرادى كه زير دييلم بوده و از گوشى هوشمند بهرهمند نبو دند بيشتر از ساير كروهها بودها

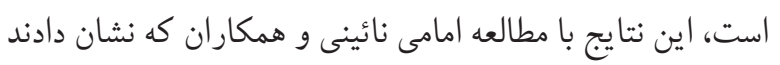

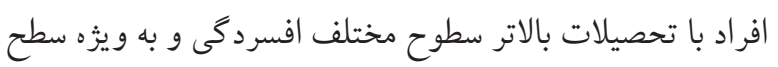

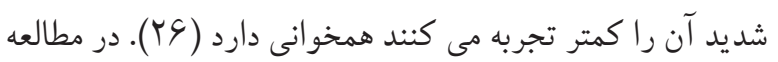

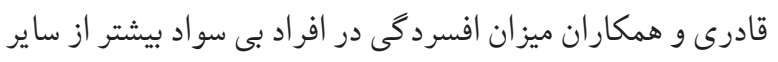
طبقها بود (YF). مطالعه لو يا 'و همكاران ( • (F) كه در آلمان انجام

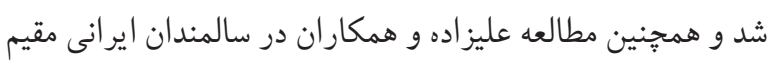

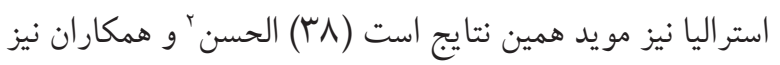
نشان دادند كه بزركسالان با سطح تحصيلات بالا احتمال ابتلا به وميه

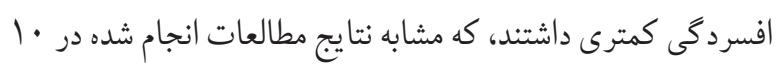

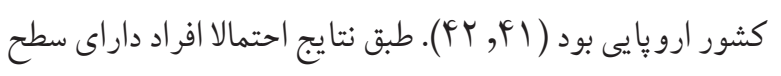

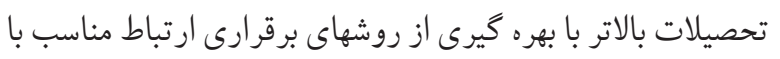

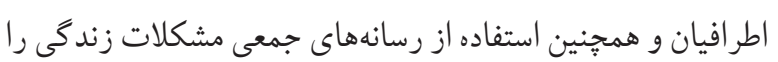
با ديد بهترى نكر يسته و ميزان افسردگى كمترى را تجربه مي كنى كندئ بررسى ارتباط ميزان افسردگى با متغير در آمد نشان داد، سالمندان

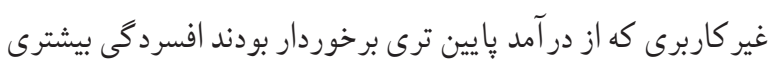

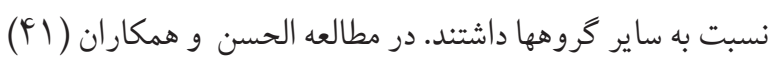

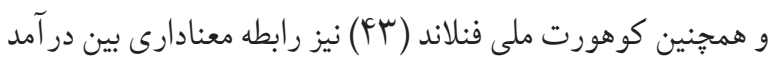

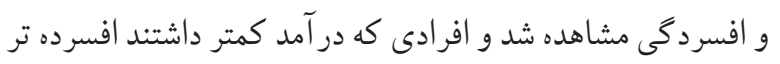

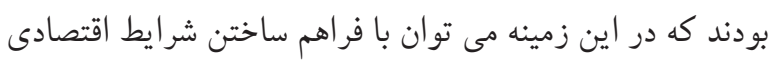

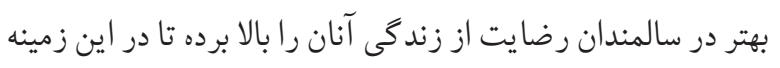
مشكلات افسردگى را احساس نكنند (FF). 


$$
\begin{aligned}
& \text { ارتقاى كيفيت زندگى آنان شد. } \\
& \text { تشكر و قدردانى } \\
& \text { اين مقاله بركرفته از طرح تحقيقاتى تصويب شده در مركز تحقيقات }
\end{aligned}
$$

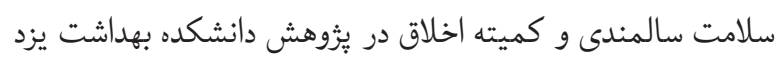

$$
\begin{aligned}
& \text { مى باشد، بدينوسيله نويسندكان از تمامى سالمندان عزيز كه ما را } \\
& \text { در اين بروره يارى نمودند تشكر و قدردانى مى نمايند. }
\end{aligned}
$$

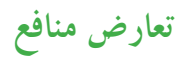

$$
\begin{aligned}
& \text { نويسندگان اعلام مى نمايند كه هيجگُنه تعارضى در بين نويسندگان }
\end{aligned}
$$

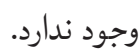

\section{Reference}

1. Elhai JD, Dvorak RD, Levine JC, Hall BJ. Problematic smartphone use: A conceptual overview and systematic review of relations with anxiety and depression psychopathology. Journal of affective disorders. 2017;207:251-9.

2. BinDhim NF, Shaman AM, Trevena L, Basyouni MH, Pont LG, Alhawassi TM. Depression screening via a smartphone app: cross-country user characteristics and feasibility. Journal of the American Medical Informatics Association. 2014;22(1):29-34.

3. Lepp A, Li J, Barkley JE, Salehi-Esfahani S. Exploring the relationships between college students' cell phone use, personality and leisure. Computers in human behavior. 2015;43:210-9.

4. Samaha M, Hawi NS. Corrigendum to "Relationships among smartphone addiction, stress, academic performance, and satisfaction with life"[Computers in Human Behavior 57 (April 2016) 321-325]. Computers in Human Behavior. 2017;75:1016.

5. Demirci K, Akgönül $M$, Akpinar A. Relationship of smartphone use severity with sleep quality, depression, and anxiety in university students. Journal of behavioral addictions. 2015;4(2):85-92.

6. Kwon M, Lee J-Y, Won W-Y, Park J-W, Min J-A, Hahn C, et al. Development and validation of a smartphone addiction scale (SAS). PloS one. 2013;8(2):e56936.

7. Cotten SR. Students' technology use and the impacts on well-being. New Directions for Student Services. 2008;2008(124):55-70.

8. Lane ND, Mohammod M, Lin M, Yang X, Lu H, Ali S, et al., editors. Bewell: A smartphone application to monitor, model and promote wellbeing. 5th international ICST conference on pervasive computing technologies for healthcare; 2011.

9. Park N, Lee $H$. Social implications of smartphone

$$
\begin{aligned}
& \text { روان از جمله افسردگى از ضروريات آتى نظام سلامت است كه بايد } \\
& \text { از زواياى مختلف بررسى شود. } \\
& \text { از نتايج اين مطالعه مى توان براى برنامه ريزى و سياست } \\
& \text { كذارى مناسب در زمينه مشكلات دوره سالمندى از جمله تنهايى } \\
& \text { و افسردگى سالمندان استفاده نمود زير ا با دكر گونىهاى اين دوره } \\
& \text { از زندگى، نيازهاى روانى -جسمى -اجتماعى سالمندان دستخوش } \\
& \text { تغيير مى شود و بايد تغييرات و نيازهاى تازه ايجاد شده را مدنظر } \\
& \text { قرار داد. همجنين با استفاده از برخى آموزشها مى توان افسردگى } \\
& \text { و ديخر عوارض اين دوران را كاسته و آن را به دوره اي مطلوب } \\
& \text { براى سالمندان تبديل كرد و با سياست كذارىهاى دولتى سبب }
\end{aligned}
$$

use: Korean college students' smartphone use and psychological well-being. Cyberpsychology, Behavior, and Social Networking. 2012;15(9):491-7.

10. Nie NH, Erbring L. Internet and society: A preliminary report. IT \& society. 2002;1(1):275-83.

11. Grimes GA, Hough MG, Mazur E, Signorella ML. Older adults' knowledge of internet hazards. Educational Gerontology. 2010;36(3):173-92.

12. Birnie SA, Horvath P. Psychological predictors of Internet social communication. Journal of Computer-Mediated Communication. 2002;7(4):JCMC743.

13. Shahbazi M, Mirkhani M, Hatamizadeh N, Rahgozar M. Evaluation of disability in Tehran elderly. Salmand. 2009;3(9):10.

14. Wilmoth J, Ferraro K. Gerontology: Perspectives and issues: Springer Publishing Company; 2013.

15. Najafi B, Arzaghi M, Fakhrzadeh H, Sharifi F, Shoaei S, Alizadeh $\mathrm{M}$, et al. Mental health status and related factors in aged population: Urban health equity assessment and response tool (Urban-HEART) study in Tehran. Iranian Journal of Diabetes and Metabolism. 2013;13(1):62-73.

16. Rondanelli M, Giacosa A, Opizzi A, Pelucchi C, La Vecchia C, Montorfano G, et al. Effect of omega-3 fatty acids supplementation on depressive symptoms and on healthrelated quality of life in the treatment of elderly women with depression: a double-blind, placebo-controlled, randomized clinical trial. Journal of the American College of Nutrition. 2010;29(1):55-64.

17. Esperanza A, Miralles R, Rius I, Fernandez B, Digon A, Arranz $\mathrm{P}$, et al. Evaluation of functional improvement in older patients with cognitive impairment, depression and/or delirium admitted to a geriatric convalescence hospitalization unit. Archives of Gerontology and Geriatrics. 2004;38:149-53.

18. Berner J, Rennemark M, Jogréus C, Berglund J. Distribution 
of personality, individual characteristics and internet usage in Swedish older adults. Aging \& mental health. 2012;16(1):119-26.

19. Carpenter BD, Buday S. Computer use among older adults in a naturally occurring retirement community. Computers in Human Behavior. 2007;23(6):3012-24.

20. Mellor D, Firth L, Moore K. Can the internet improve the well-being of the elderly? Ageing international. 2008;32(1):25-42.

21. Campbell SW, Kwak N. Mobile communication and social capital: An analysis of geographically differentiated usage patterns. New Media \& Society. 2010;12(3):435-51.

22. Yang S, Kurnia S, Smith SP, editors. The impact of mobile phone use on individual social capital. 2011 44th Hawaii International Conference on System Sciences; 2011: IEEE.

23. Saboor M, Sahaf R, Sum S. Application of the Internet and its Association with Loneliness among Retired Teachers. SALMAND. 2014;9(1).

24. Malakouti K, Fathollahi P, Mirabzadeh A, Salavati M, Kahani S. Validation of geriatric depression scale (GDS-15) in Iran. Research in Medicine. 2006;30(4):361-9.

25. Malakouti SK, Fatollahi P, Mirabzadeh A, Salavati M, Zandi T. Reliability, validity and factor structure of the GDS-15 in Iranian elderly. International Journal of Geriatric Psychiatry: A journal of the psychiatry of late life and allied sciences. 2006;21(6):588-93.

26. Emaminaeini M, Bakhtiyari M, Hatami H, Khodakarim S, Sahaf R. Depression and perceived social support in the elderly. Iranian J Ageing. 2017;12(2):192-207.

27. Alipour F, Sajadi H, Forouzan A, Nabavi H, Khedmati E. The role of social support in the anxiety and depression of elderly. Iranian Journal of Ageing. 2009;4(1):0-.

28. Elhai JD, Levine JC, Dvorak RD, Hall BJ. Fear of missing out, need for touch, anxiety and depression are related to problematic smartphone use. Computers in Human Behavior. 2016;63:509-16.

29. Lemola S, Perkinson-Gloor N, Brand S, Dewald-Kaufmann JF, Grob A. Adolescents' electronic media use at night, sleep disturbance, and depressive symptoms in the smartphone age. Journal of youth and adolescence. 2015;44(2):405-18.

30. Dalbudak E, Evren C, Aldemir S, Coskun KS, Ugurlu H, Yildirim FG. Relationship of internet addiction severity with depression, anxiety, and alexithymia, temperament and character in university students. Cyberpsychology, Behavior, and Social Networking. 2013;16(4):272-8.

31. Demirci K, Orhan H, Demirdas A, Akpinar A, Sert $H$. Validity and reliability of the Turkish Version of the Smartphone Addiction Scale in a younger population. Klinik Psikofarmakoloji Bülteni-Bulletin of Clinical Psychopharmacology. 2014;24(3):226-34.

32. Hwang K-H, Yoo Y-S, Cho O-H. Smartphone overuse and upper extremity pain, anxiety, depression, and interpersonal relationships among college students. The Journal of the Korea Contents Association. 2012;12(10):365-75.

33. Alizadeh M, Hoseini M, Shojaeizadeh D, Rahimi A, Arshinchi M, Rohani H. Assessing anxiety, depression and psychological wellbeing status of urban elderly under represent of Tehran metropolitan city. Iranian Journal of Ageing. 2012;7(3):66-73.

34. Ghaderi S, Sahaf R, Mohammadi Shahbalaghi F, Ansari G, Gharanjic A, Ashrafi K, et al. Prevalence of depression in elderly Kurdish community residing in Boukan, Iran. Iranian Journal of Ageing. 2012;7(1):57-66.

35. Park N, Lee $\mathrm{H}$. Nature of youth smartphone addiction in Korea. 2014

36. Gao Y, Li A, Zhu T, Liu X, Liu X. How smartphone usage correlates with social anxiety and loneliness. PeerJ. 2016;4:e2197.

37. Ran W, Lo V. Staying connected while on the move: Cell phone use and social connectedness. New Media \& Society. 2006;8(1):53-72.

38. Alizadeh-Khoei M, Khosbin S, Khavarpour F. Assessing quality of life, well being and depression among Iranian ederly in Australia. Iranian Journal of Ageing. 2010;4(4):0-.

39. Khodadady N, Sheikholeslami F, Rezamasuoleh S, Yazdani M. Rate of depression in late-life in superannuated government employed center of? Guilan University of medical sciences. 2007.

40. Luppa M, Sikorski C, Luck T, Weyerer S, Villringer A, König $\mathrm{HH}$, et al. Prevalence and risk factors of depressive symptoms in latest life-results of the Leipzig Longitudinal Study of the Aged (LEILA 75+). International Journal of Geriatric Psychiatry. 2012;27(3):286-95.

41. Alhassan AA, Alqadhib EM, Taha NW, Alahmari RA, Salam $M$, Almutairi AF. The relationship between addiction to smartphone usage and depression among adults: a cross sectional study. BMC psychiatry. 2018;18(1):148.

42. Ladin K. Risk of late-life depression across 10 European Union countries: deconstructing the education effect. Journal of aging and health. 2008;20(6):653-70.

43. Koivumaa-Honkanen $\mathrm{H}$, Kaprio J, Honkanen $\mathrm{R}$, Viinamäki $\mathrm{H}$, Koskenvuo M. Life satisfaction and depression in a 15year follow-up of healthy adults. Social psychiatry and psychiatric epidemiology. 2004;39(12):994-9.

44. Boumosleh JM, Jaalouk D. Depression, anxiety, and smartphone addiction in university students-A cross sectional study. PloS one. 2017;12(8):e0182239.

45. Adams S, Kisler T. CYBERPSYCHOLOGY, BEHAVIOR, AND SOCIAL NETWORKING. Sleep Quality as a Mediator Between Technology-Related Sleep Quality, Depression, and Anxiety. 2013;16(1):25-30. 